\title{
Image-guid ed thoracic pedicle screw placement: a technical study in cadavers and preliminary clinical experience
}

\author{
Kee D. Kim, M.D., J. Patrick Johnson, M.D., AND Jesse D. Babbitz, M.D. \\ Department of Neurological Surgery, University of California, Davis, Sacramento; and Division of \\ Neurosurgery, University of California, Los Angeles, Los Angeles, California
}

\begin{abstract}
Object. Thoracic pedicle screw fixation is effective and reliable in providing short-segment stabilization. Although the procedure is becoming more widely used, accurate insertion of the screws is difficult due to the small dimensions of thoracic pedicles, and the associated risk is high due to the proximity of the spinal cord. In previous studies authors have shown the accuracy of image-guided lumbar pedicle screw placement, but there have been no reported investigations into the accuracy of image-guided thoracic pedicle screw placement. The authors report their experience with such an investigation.

Methods. To evaluate the accuracy of image-guided thoracic pedicle screw placement in vitro and in vivo, thoracic pedicle screws were placed with an image-guidance system in five human cadavers and 10 patients. In cadavers, the accuracy of screw placement was assessed by postoperative computerized tomography and visual inspection and in patients by postoperative imaging studies. Of the 120 pedicle screws placed in five cadavers pedicle violation occurred in 23 cases $(19.2 \%)$; there was one pedicle violation $(4.2 \%)$ in each of the last two cadavers. Of the 45 pedicle screws placed in 10 patients, pedicle violations occurred in three $(6.7 \%)$.

Conclusions. In comparison with historical controls, the accuracy of thoracic pedicle screw placement is improved with the use of an image-guidance system. It allows the surgeon to visualize the thoracic pedicle and the surrounding structures that are normally out of the surgical field of view. The surgeon, however, must be aware of the limitations of an image-guidance system and have a sound basic knowledge of spinal anatomy to avoid causing serious complications.
\end{abstract}

\section{KEY WORDS • neuronavigation • pedicle screw • thoracic spine • computer-aided surgery}

The use of pedicle screw fixation has become a popular procedure in patients with trauma-induced fractures, as well as in reconstruction after treatment of degenerative, scoliotic, and neoplastic spinal diseases. For those with three-column injury, pedicle screw fixation provides the only means to accomplish immediate immobilization of all three columns without resorting to anterior and posterior procedures. Biomechanically, it is superior to instrumentation in which hooks are used, and it allows application of significant corrective forces. ${ }^{12,18,22}$ Moreover, pedicle screw fixation allows a fusion of fewer motion segments and does not require hardware that will intrude into the spinal canal.

Despite all of the advantages, thoracic pedicle screw placement is infrequently performed due to the difficulty of accurate screw placement. Thoracic pedicles are smaller and more variable in dimension compared with lumbosacral pedicles. ${ }^{15,19}$ The risk from screw misplacement is higher because of the proximity of the spinal cord. ${ }^{4}$ In-

Abbreviations used in this paper: $\mathrm{CT}=$ computerized tomography; $2 \mathrm{D}=$ two-dimensional; $3 \mathrm{D}=$ three-dimensional.. traoperative fluoroscopic imaging of the thoracic pedicle is difficult because of radiographic obscuration from the rib cage. Therefore, it comes as no surprise that the rate of reported thoracic pedicle wall violation ranges from 15.9 to $54.7 \% .^{12,20,21}$

An image-guidance system is an obvious adjunctive tool for thoracic pedicle screw placement. The use of image guidance has been reported to increase the accuracy of lumbar pedicle screw placement..$^{3,7,11,17}$ No studies have been performed specifically to study pedicle screw placement in the thoracic spine. We report our technical study in five human cadavers and our early clinical experience in 10 patients in whom image-guided thoracic pedicle screw placement was conducted.

\section{CLINICAL MATERIAL AND METHODS}

\section{Patient Population}

Five cadavers (two male and three female individuals who were elderly at the time of death) and 10 patients underwent image-guided thoracic pedicle screw placement. The technical study was conducted first in cadavers at 
K. D. Kim, J. P. Johnson, and J. D. Babbitz

TABLE 1

Summary of data in 10 patients in whom 45 thoracic pedicle screws were placed

\begin{tabular}{|c|c|c|c|c|c|}
\hline $\begin{array}{l}\text { Case } \\
\text { No. }\end{array}$ & $\begin{array}{c}\text { Age (yrs), } \\
\text { Sex }\end{array}$ & Injury & $\begin{array}{l}\text { Fusion } \\
\text { Levels }\end{array}$ & $\begin{array}{l}\text { No. of } \\
\text { Screws }\end{array}$ & Perforation \\
\hline 1 & $32, \mathrm{M}$ & T11-12 compression fracture w/ progressive painful kyphosis & T10-L1 & 6 & none \\
\hline 3 & $40, \mathrm{~F}$ & T12-L1 fracture-dislocation w/ L-1 burst fracture & T11-L3 & 4 & none \\
\hline 4 & $50, \mathrm{~F}$ & lumbar spinal stenosis $\mathrm{w} /$ scoliosis & T12-L5 & 2 & none \\
\hline 5 & $30, \mathrm{M}$ & L-1 burst fracture & T11-L3 & 2 & none \\
\hline 7 & $20, \mathrm{M}$ & T-9 fracture-dislocation & $\mathrm{T} 7-11$ & 8 & none \\
\hline 8 & $24, \mathrm{~F}$ & T10-11 fracture-dislocation & T9-L1 & 6 & none \\
\hline 9 & $66, \mathrm{M}$ & L-1 burst fracture, T12-L1 fracture-dislocation & T11-L2 & 4 & 1 lat rt T-11 \\
\hline 10 & $37, \mathrm{~F}$ & $\mathrm{~T}-12$ burst fracture & T11-L1 & 4 & 1 medial rt T-11 \\
\hline
\end{tabular}

the University of California, Los Angeles, and then in 10 patients treated by the lead author (K.D.K.) from February 1999 to March 2000 at the University of California, Davis. There were seven men and three women, who ranged in age from 20 to 66 years (mean age 36.7 years). The pathological conditions included trauma (eight patients), degenerative disease (one patient), and tumor (one patient). All but one patient required an extension of the fusion to either the cervical or lumbar region (Table 1).

\section{Preoperative Preparation}

Computerized tomography scans of the spine were obtained in 1-mm slices, and the data were imported into one of the computer workstations: the Optical Tracking System (Radionics, Burlington, MA) for the cadavers and the Stealth Station (Medtronic, Broomfield, CO) for the patients. Both systems generated 3D images of the spine and standard 2D orthogonal images on the computer monitor.

\section{Surgical Technique}

After making a midline incision, posterior subperiosteal dissection was performed at the relevant levels to expose the spinous processes, laminae, and transverse processes. A reference frame was attached to the spinous process of each vertebra studied, and the registration was performed using the standard techniques. ${ }^{1,6,9}$ The registration step was repeated until the match was determined to be adequate. $^{9}$ In the cadavers, our registration achieved a mean error of less than $1.5 \mathrm{~mm}$ whereas in patients the mean error was below $0.7 \mathrm{~mm}$. The accuracy of the match between preoperative CT scans and postexposure anatomy was assessed by placing the probe onto an exposed anatomical landmark as the computer screen displayed the perceived location of that probe.

A power drill with a bit diameter of 2.5 or $3.5 \mathrm{~mm}$ was tracked by the image-guidance system. ${ }^{10}$ The computer monitor displayed the location of the drill bit and its trajectory on the axial, sagittal, coronal, and 3D images. Additional navigation views in relation to the plane of the instrument were also used. Each thoracic pedicle pilot hole entry point and trajectory was initiated, and the pedicle entered with a drill under image guidance. The pilot hole was then tapped and the screws (ranging in diameter from $3.5-6.5 \mathrm{~mm}$ ) were placed, both without image guid- ance. Prior to insertion of the screw, a blunt-tipped imageguided probe was inserted into the proximal portion of the tap hole to assess the trajectory. The screw sizes varied due to the large differences in the pedicle width. The largest available screws that the pedicles could accommodate were used.

\section{Postoperative Evaluation}

A total of 120 thoracic pedicle screws was placed in the five cadavers. The accuracy was evaluated by postoperative CT scanning and visual inspection. The spine was removed from each cadaver and stripped of all the soft tissues. To assess lateral pedicle wall violation, the rib head attachments to the spine were removed using a rongeur. Using a saw to bisect the spine, the integrity of the medial, superior, and inferior pedicles was then evaluated.

A total of 45 thoracic pedicle screws was placed in 10 patients. The accuracy of the pedicle screw placement was evaluated postoperatively by CT scanning and anteroposterior and lateral radiography. In all patients flexion-extension x-ray films were obtained 3 months after surgery except in Cases 5 and 8 because the patients were lost to follow up.

\section{RESULTS}

Of 120 thoracic pedicle screws inserted in cadavers, 23 $(19.2 \%)$ resulted in pedicle wall violation (Table 2 ). There was a progressive decline in the perforation rate from $24 \%$ in the first cadaver to $4 \%$ in the last treated cadaver. A greater number of medial perforations (15 of 21) occurred than lateral perforations (eight of 21). Although seven

TABLE 2

Thoracic pedicle wall perforation in five cadavers

\begin{tabular}{cclc}
\hline \hline $\begin{array}{c}\text { Cadaver } \\
\text { No. }\end{array}$ & $\begin{array}{c}\text { No. of } \\
\text { Screws }\end{array}$ & $\begin{array}{c}\text { Direction of } \\
\text { Perforation(s) }\end{array}$ & $\begin{array}{c}\text { Total No. of } \\
\text { Perforation(s) }\end{array}$ \\
\hline 1 & 24 & 2 lat, 7 medial & 9 \\
2 & 24 & 4 lat, 4 medial & 8 \\
3 & 24 & 4 medial & 4 \\
4 & 24 & 1 lat & 1 \\
5 & 24 & 1 lat & 1 \\
\hline
\end{tabular}




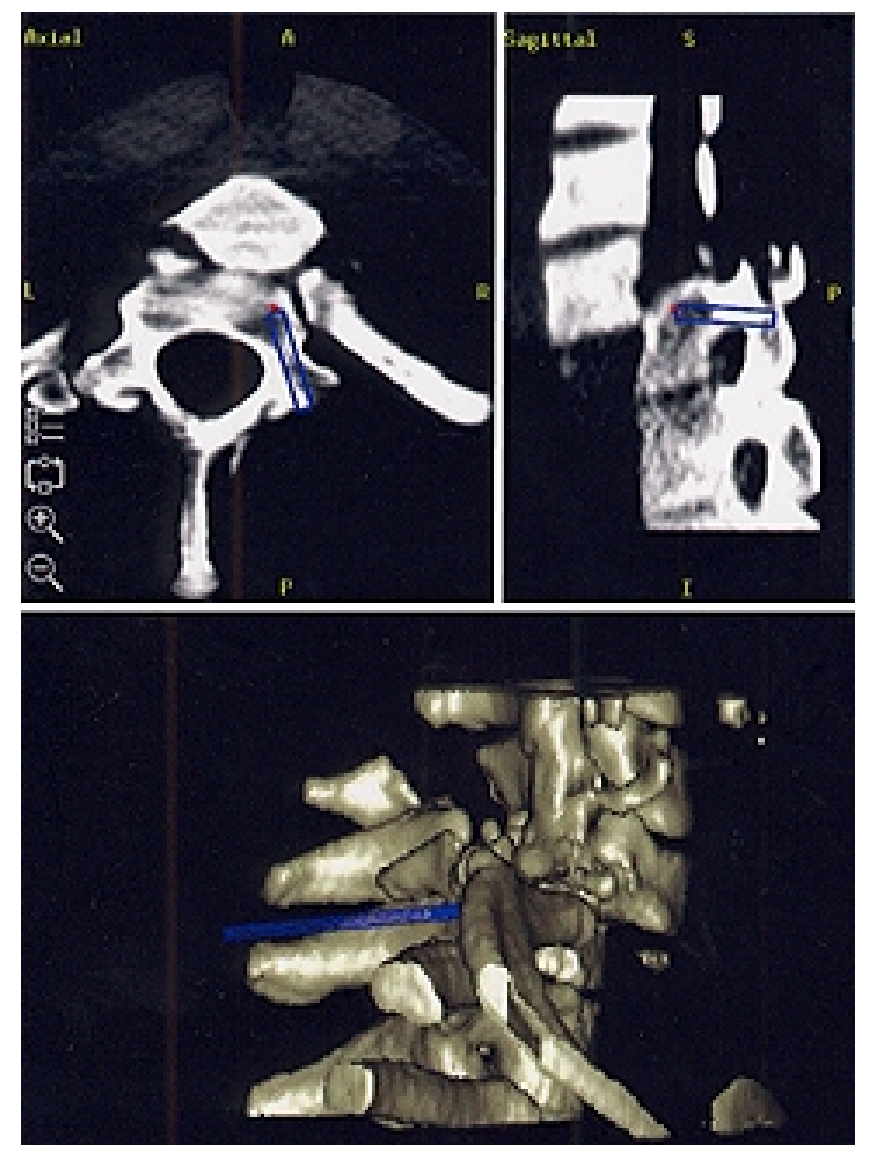

Fig. 1. Case 6. Orthogonal 2D and 3D reconstructed images obtained during surgical planning. The blue cylinder represents the intended trajectory of the right T-1 pedicle screw.

major perforations occurred medially, we did not find obvious injury to the dura. There was no superior or inferior pedicle wall perforation. No significant differences in the rate of pedicle wall violation were noted among the different thoracic levels.

Of 45 thoracic pedicle screws placed in the 10 patients, three $(6.7 \%)$ resulted in pedicle wall violation, as demonstrated on postoperative images (Table 1). There were two lateral and one medial perforation, all minor (defined as only the threads of the screw extruding from the cortex).

One complication was recognized: the patient in Case 6 had a seroma and wound dehiscence that was repaired and healed without sequelae.

\section{ILLUSTRATIVE CASES}

\section{Case 6}

This 22-year-old schizophrenic man leapt from a bridge, suffering a C7-T1 fracture-dislocation and T-12 burst fracture; the results of the initial examination were consistent with a complete C-7 spinal cord injury. In addition, he sustained multiple extremity fractures and abdominal injuries.

He underwent a posterior $\mathrm{C} 4-\mathrm{T} 3$ fusion. The fixation construct consisted of lateral mass screws placed at $\mathrm{C}-4$, C-5, and C-6 and pedicle screws placed at C-7, T-1, and

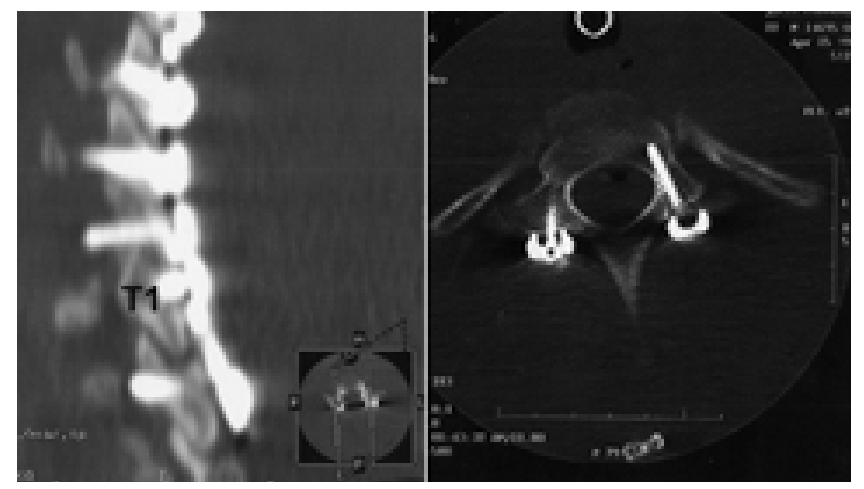

Fig. 2. Case 6. Postoperative 2D reconstructed sagittal (left) and axial (right) CT scans demonstrating restoration of sagittal alignment and accurate pedicle screw placement at T-1.

T-2. The Stealth Station was used for image-guided placement of all pedicle screws (Fig. 1).

Postoperative CT scanning revealed good fracture reduction (Fig. 2 left) and accurate screw placement (Fig. 2 right), except for one minor lateral pedicle perforation at $\mathrm{T}-2$. He was managed in a cervical collar for 3 months. At 3 months follow-up examination, flexion-extension x-ray films demonstrated no instability and good alignment of the spine.

\section{Case 9}

This 66-year-old man was struck by a falling tree as he walked down the street. He presented to the emergency room insensate and flaccid, with a complete T-12 spinal cord injury and an L-1 burst fracture with T12-L1 fracture-dislocation. In addition, he suffered a perineal puncture wound, hemopneumothoraces, multiple extremity fractures, and a renal artery avulsion.

He underwent image-guided posterior thoracolumbar fusion in which pedicle screws were inserted bilaterally from T-11 to L-2 (Fig. 3 left). Postoperative CT scanning

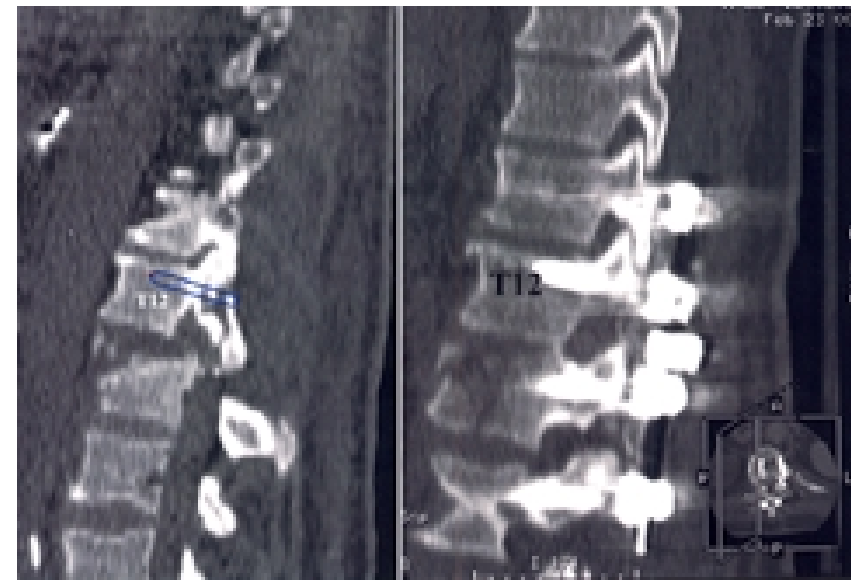

Fig. 3. Case 9. Left: Preoperative, 2D reconstructed CT scan obtained during surgical planning. The blue cylinder represents the proposed trajectory of the left T-11 pedicle screw. Right: Postoperative $2 \mathrm{D}$ reconstructed $\mathrm{CT}$ scan demonstrating restoration of sagittal alignment. 


\section{K. D. Kim, J. P. Johnson, and J. D. Babbitz}

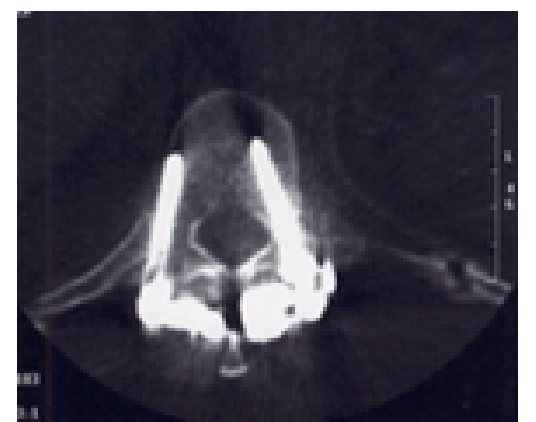

Fig. 4. Case 9. Postoperative axial CT scan revealing the minor lateral pedicle wall perforation in the right $\mathrm{T}-11$ pedicle and good screw placement on the left.

demonstrated good fracture reduction (Fig. 3 right) but a minor lateral pedicle perforation had occurred at T-11 (Fig. 4). Follow-up flexion-extension x-ray films obtained at 3 months demonstrated evidence of solid arthrodesis and no segmental instability.

\section{DISCUSSION}

Unlike in the lumbar spine, both the recommended entry point and trajectory for thoracic pedicle screw placement differ significantly among the experts. ${ }^{2,5,13,14,16} \mathrm{~A}$ consistent entry point and trajectory are difficult to predict because of the variable anatomy of the thoracic pedicles. ${ }^{15,19}$ After performing a morphometric study, Panjabi, et al., ${ }^{15}$ concluded that the shape and orientation of thoracic pedicles varied significantly. Furthermore, the interference from the rib cage and the small size of the pedicles often make good intraoperative fluoroscopic visualization of the thoracic pedicles impossible. Anatomical variation induced by degenerative changes, trauma, scoliosis, or tumor involvement makes accurate thoracic pedicle screw placement even more difficult.

In a report on thoracic pedicle screw placement in cadavers, Vaccaro and colleagues ${ }^{20}$ did not use image guidance. The five experienced spine surgeons reported a $41 \%$ pedicle perforation rate. $\mathrm{Xu}$, et al., ${ }^{21}$ reported thoracic pedicle perforation rate of $54.7 \%$ when using the Roy-Camille technique; when they performed partial thoracic laminectomy to palpate the medial and superior walls of the pedicle, the perforation rate decreased to $15.9 \%$.

For thoracic pedicle screw placement in which even a minor deviation in the screw trajectory may result in a pedicle perforation, any improved visualization is invaluable. A CT-based image-guidance system provides the surgeon with a view of the pedicle and surrounding structures in multiple planes. For each pedicle, an ideal entry point and trajectory for screw placement may be chosen. An image-guidance system is able to track and provide updated information about the location of the probe to avoid injury to the spinal cord., ${ }^{4,8,9}$

In ideal circumstances, the use of an image-guidance system should eliminate all pedicle perforation. This, however, has not been our experience. The key step is registration. Here the preoperative image is correlated intraoperatively with the patient's anatomy. If the correlation is suboptimal, the displayed image does not accurately re- flect the position of the probe. This was reflected in the increased perforation rate seen in cadavers compared with patients, most likely due to the higher mean error achieved during registration in the former. In thoracic pedicles, in which the room for error is small, minor inaccuracies can result in significant error and possible serious complications.

For the first three cadavers, our pedicle perforation rate was higher than that reported by others for lumbar pedicle screw placement. ${ }^{11,17}$ With any new technology there is an associated learning curve, and we found this to be the case with the image-guidance system. Some of the problems were related to the hardware that was used. The early reference frame was so bulky that it got in the way of the surgical instrument, and it could be inadvertently moved independent of the spinal segment, rendering the images on the video monitor inaccurate.

Prior to and during an image-guidance system-assisted procedure, the surgeon should be conscious of the system's limitations. If the surgeon blindly trusts what is displayed on the computer monitor, serious injury may be caused to the patient and the construction may be biomechanically unsound.

\section{CONCLUSIONS}

Thoracic pedicle screw placement allows strong fixation of the spine without the need for long-segment fusion. It is, however, technically challenging because of the small size and variable dimensions of thoracic pedicles. An image-guidance system provides multiplanar views of the pedicle, allowing the surgeon to select the optimum point of entry and trajectory to traverse the pedicle without perforating the wall. If used properly, an image-guidance system may prove to reduce significantly the pedicle perforation rate and ultimately reduce the risks of thoracic pedicle screw insertion.

\section{References}

1. Amiot LP, Labelle H, DeGuise JA, et al: Computer-assisted pedicle screw fixation. A feasibility study. Spine 20: 1208-1212, 1995

2. An HS, Gordin R, Renner K: Anatomic considerations for plate-screw fixation of the cervical spine. Spine 16 (Suppl): S548-S551, 1991

3. Carl AL, Khanuja HS, Sachs BL, et al: In vitro simulation. Early results of stereotaxy for pedicle screw placement. Spine 22: 1160-1164, 1997

4. Ebraheim NA, Jabaly G, Xu R, et al: Anatomic relations of the thoracic pedicle to the adjacent neural structures. Spine 22: 1553-1557, 1997

5. Ebraheim NA, Xu R, Ahmad M, et al: Projection of the thoracic pedicle and its morphometric analysis. Spine 22:233-238, 1997

6. Glossop ND, Hu RW, Randle JA: Computer-aided pedicle screw placement using frameless stereotaxis. Spine 21: 2026-2034, 1996

7. Kalfas IH, Kormos DW, Murphy MA, et al: Application of frameless stereotaxy to pedicle screw fixation of the spine. J Neurosurgery 83:641-647, 1995

8. Kaus M, Steinmeier R, Sporer T, et al: Technical accuracy of a neuronavigation system measured with a high-precision mechanical micromanipulator. Neurosurgery 41:1431-1437, 1997 
9. Kim KD, Babbitz JD, Mimbs J: Imaging-guided costotransversectomy for thoracic disc herniation. Neurosurg Focus 9 (4): Article 7, 2000

10. Kim KD, Johnson JP, Masciopinto JE, et al: Universal calibration of surgical instruments for spinal stereotaxy. Neurosurgery 44: 173-178, 1999

11. Laine T, Schlenzka D, Makitalo K, et al: Improved accuracy of pedicle screw insertion with computer-assisted surgery. A prospective clinical trial of 30 patients. Spine 22:1254-1258, 1997

12. Liljenqvist UR, Halm HF, Link TM: Pedicle screw instrumentation of the thoracic spine in idiopathic scoliosis. Spine 22: 2239-2245, 1997

13. Louis R: Spinal internal fixation with Louis instrumentation, in An HS, Cotler JM, (eds): Spinal Instrumentation. Baltimore: Williams \& Wilkins, 1992, pp 183-196

14. Magerl FP: Stabilization of the lower thoracic and lumbar spine with external skeletal fixation. Clin Orthop 189:125-141, 1984

15. Panjabi MM, O'Holleran JD, Crisco JJ III, et al: Complexity of the thoracic spine pedicle anatomy. Eur Spine J 6: 19-24, 1997

16. Roy-Camille R, Mazel C, Laville C: Roy-Camille posterior screw plate fixation for cervical, thoracic, lumbar spine and sacrum, in An HS, Cotler JM, (eds): Spinal Instrumentation. Baltimore: Williams \& Wilkins, 1992, pp 167-182

17. Schwarzenbach O, Berlemann U, Jost B, et al: Accuracy of computer-assisted pedicle screw placement. An in vivo computed tomography analysis. Spine 22:452-458, 1997
18. Suk SI, Lee CK, Min HJ, et al: Comparison of Cotrel-Dubuousset pedicle screws and hooks in the treatment of idiopathic scoliosis. Int Orthop 18:341-346, 1994

19. Vaccaro AR, Rizzolo SJ, Allardyce TJ, et al: Placement of pedicle screws in the thoracic spine. Part I: morphometric analysis of the thoracic vertebrae. J Bone Joint Surg (Am) 77: 1193-1199, 1995

20. Vaccaro AR, Rizzolo SJ, Balderston RA, et al: Placement of pedicle screws in the thoracic spine. Part II: an anatomical and radiographic assessment. J Bone Joint Surg (Am) 77: 1200-1206, 1995

21. Xu R, Ebraheim NA, Ou Y, et al: Anatomic considerations of pedicle screw placement in the thoracic spine. Roy-Camille technique versus open-lamina technique. Spine 23:1065-1068, 1998

22. Zindrick MR, Wiltse LL, Widell EH, et al: A biomechanical study of intrapeduncular screw fixation in the lumbosacral spine. Clin Orthop 203:99-112, 1986

Manuscript received December 15, 2000.

Accepted in final form January 26, 2001.

Address reprint requests to: Kee D. Kim, M.D., Department of Neurological Surgery, 4860 Y Street \#3740, Sacramento, California 95817. email:kdkim@ucdavis.edu. 